\title{
Toward the formation of parameters influencing the quality of low-rise residential buildings
}

\author{
Azary Lapidus ${ }^{1}$, Yves Ndayiragije ${ }^{1 *}$ and Alexander Stepanov ${ }^{1}$ \\ Moscow State University of Civil Engineering, Moscow, 129337, Russia
}

\begin{abstract}
The construction industry occupies a significant place in the development of any country. The success level of construction projects largely depends on its quality. Poor performance of work leads to different losses. Effective quality management delivers customer satisfaction and value, reduces visible and less visible cost of poor quality. The article aims to identify the main parameters influencing the quality of low-rise residential buildings using expert opinion method. At the first stage, a literature review was conducted, which resulted in a list of 54 individual indicators of technical solutions that affect the quality of low-rise apartment buildings. These quality indicators have different degrees of influence. Experts identified indicators that have a greater impact on the comprehensive quality indicator. Then, the list was shortened up to 34 individual indicators. The survey was conducted in construction companies, research centers, and construction universities. The development of a comprehensive quality index contributes to the achievement of design decisions in construction of residential buildings. The methodological scheme of the study is shown. Using the method of exploratory factor analysis, all indicators were grouped into 7 groups. A conceptual measurement model is defined. Furthermore, a structural model to determine the influence weights of each individual indicator on the corresponding group of factors is shown.
\end{abstract}

\section{Introduction}

Construction industry occupies a significant place in the development of any country. The level of success of construction projects largely depends on its quality. Poor performance of work leads to different losses such as reputation of the industry and individual businesses; economical losses; and human impact. Effective quality management delivers customer satisfaction and value, reduces visible and less visible cost of poor quality $[1,2]$. Visible cost is related to the cost of rework, inspection, scrap, defects and overruns. Less visible cost can be product failure in the field, time lost due to accidents, extra operations like touch up, trimming, retrofit cost due to design deficiencies, equipment failures, unnecessary procedures, inappropriate job specifications. Quality costs are split into four different categories: costs of prevention, costs of appraisal, costs of internal failure, and costs of

\footnotetext{
* Corresponding author: yndayiragije@yahoo.fr
} 
external failure. Likewise, in other industry improving quality and customer satisfaction should have high priority, alongside safety and health. [3, 4]

Improving the efficiency of construction projects, thereby reducing defects in the construction process and during operation are of concern to customers in the first stage and of course the state. Currently, in Burundi there is no regulation and monitoring of construction processes by the state. As a result, cases of buildings destruction during construction are multiplied; the period of reliable operation of structures is sharply reduced. The need for repairs appears in the first five years of operation, which minimizes the attractiveness of investment in the construction industry. Figure 1 shows an example of the collapse of a three-storey building located in the Kiyange district of Bujumbura. The reason for the collapse was the destruction of the columns of the first floor due to an additional non-project floor being built without carrying out a verification calculation of building structures.
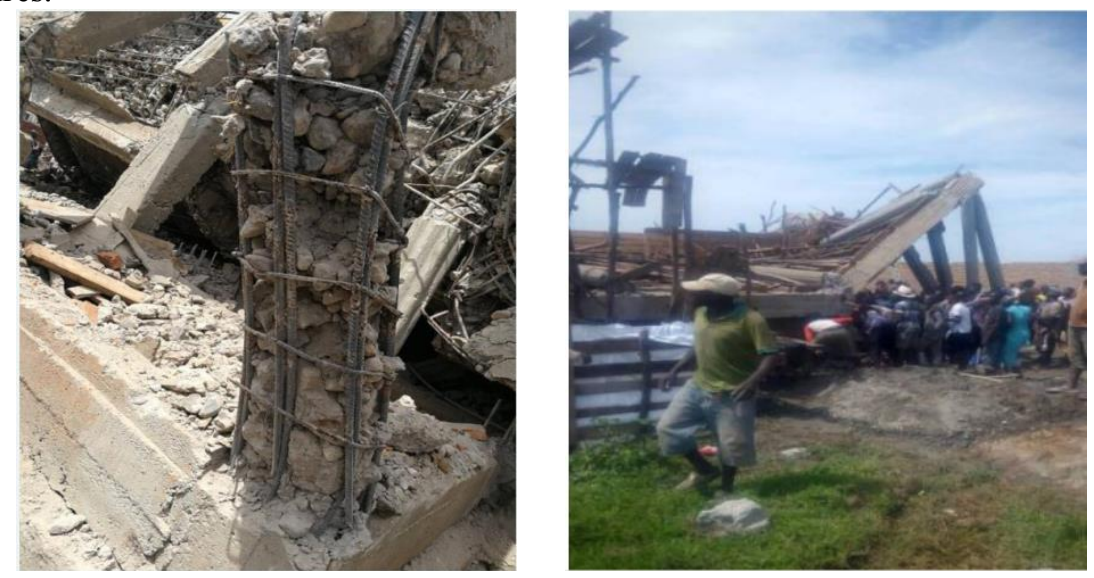

Fig.1. The collapse of 3-storey house in the Kiyange quarter,city of Bujumbura

Many researches have been conducted to promote the quality culture in construction industry $[5,6,7]$. It had been shown that quality relates to the way people behave and the way an organization operates. Moreover, there are other issues to be considered such as legislative requirements, training, employee engagement, focus on cost and time, supervisory controls $[8,9,10]$. Effective quality management can be seen as a cost. However, it can also be seen as a vital cost-saving process that only pays for itself. Therefore, all stages of the life cycle of the construction process must be monitored with high accuracy using a systematic approach. During the implementation of the construction project, various interrelated systemic problems are solved. These include design, procurement of materials, construction, quality assurance and quality control, personnel management, logistics, and environmental protection and safety [11, 12, 13]. An integrated approach to solving these problems contributes to mass housing construction, thereby increasing the quality, durability, safety, environmental performance, energy efficiency and affordability of homes. As never before, it is necessary for the construction industry to develop competitive organizational, technological and economic solutions that enable the satisfaction of the clients. Within the framework of the research, quality is understood as the characteristics of a building that depend on the project documentation. Project documentation is created by professionals based on the customer's needs and within the framework of existing regulatory documents. The Comprehensive quality indicator is a generalized indicator that contributes to the achievement of design solutions. The purpose of the study is to develop a methodology for determining the complex quality indicator of technical solutions for the construction of low-rise apartment buildings. 
To achieve this goal, the following tasks have to be solved:

- conducting an expert survey to identify factors that affect the quality of residential buildings;

- analysis of factors impact on the quality of residential buildings;

- analysis of the influence of technical factors on the complex quality indicator of lowrise apartment buildings;

- development of a methodology to form the complex quality indicator of technical solutions for the construction of low-rise apartment buildings.

The following methodological scheme of the study was used (Fig. 2).

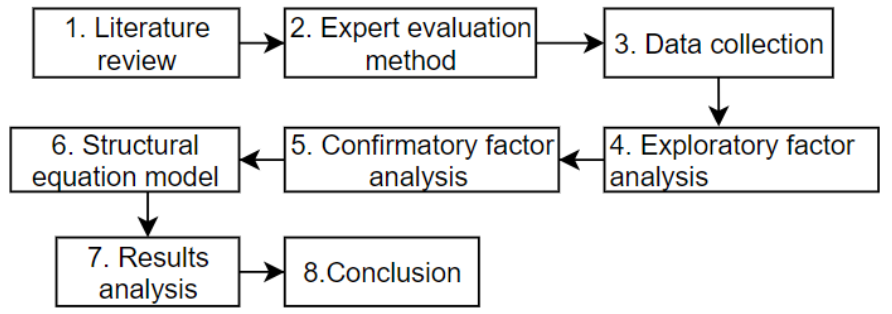

Fig. 2. Main research stages

At the first stage, a literature review was conducted, which resulted in a list of 54 individual indicators of technical solutions that affect the quality of low-rise apartment buildings. These quality indicators have different degrees of influence. Experts identified indicators that have a greater impact on the comprehensive quality indicator. Then, the list was shortened up to 34 individual indicators. The survey method is based on filling out special questionnaires by construction experts. We used the Likert scale to determine experts ' opinions. The survey was conducted in construction companies, research centers, and construction universities.

Table 1. Respondents characteristics

\begin{tabular}{|c|l|l|l|}
\hline & & Number & Percentage \\
\hline \multirow{4}{*}{ Category } & Professors & 42 & 17 \\
\cline { 2 - 4 } & Construction consultant & 13 & 5 \\
\cline { 2 - 4 } & Architect & 6 & 2 \\
\cline { 2 - 4 } & Structure engineers & 31 & 13 \\
\cline { 2 - 4 } & Designer engineers & 45 & 18 \\
\cline { 2 - 4 } & Field engineers & 98 & 39 \\
\cline { 2 - 4 } & General manager & 8 & 3 \\
\cline { 2 - 4 } & Researchers & 7 & 34 \\
\hline \multirow{4}{*}{$\begin{array}{c}\text { Type of } \\
\text { organi- } \\
\text { zation }\end{array}$} & Ministry of construction & 32 & 36 \\
\cline { 2 - 4 } & Higher education institution & 87 & 6 \\
\cline { 2 - 4 } & Property developer & 28 & 31 \\
\cline { 2 - 4 } & Construction company & 92 & 36 \\
\cline { 2 - 4 }
\end{tabular}

Using the method of exploratory factor analysis, all indicators were grouped into 7 groups:

I. Group of factors related to project participants (UP12, UP12, UP13):

1. Cooperation between project participants;

2. Contractors ' Portfolio (qualifications and experience in construction, completed projects, staff qualifications); 
3. Organization of contractors (monitoring and management program with clear contracts).

II. Group of factors related to design (P21, P22, P23, P24, P25, P26):

1. Completeness of the design specification;

2. Local building codes;

3. Completeness of engineering surveys (geological, ecological, calculation analysis,...);

4. Limited design period set by the client;

5. The experience and expertise of designers;

6. Completeness of technical and organizational guidance;

7. Use of modern software.

III. Group of factors related to materials (CM31, CM32, CM33, CM34, CM35):

1. Use of non-certified materials;

2. Rules of materials transportation;

3. Rules of materials storage;

4. Unavailability of construction materials;

5. Price fluctuations.

IV. Group of factors related to construction (Spr41, Spr42,...):

1. Availability of a construction permit;

2. Availability of working documents;

3. Qualification and experience of engineers in construction;

4. Geodetic support of works (breakdown of the building on the ground according to the project);

5. Organization of resources (labor, mechanisms) on the construction site;

6. Limited construction period set by clients;

7. The degree of mechanization of construction works;

8. Climatic conditions on the construction site.

V. A group of factors related to the quality culture (UP12, UP12, UP13, ...):

1. Quality culture (planning of measures for quality assurance);

2. The availability of quality control breakdown;

3. Incentive system for quality work (criteria for rewarding employees for the quality of work performed);

4. Availability of the state quality control system;

5. Availability of quality control service at the construction site.

VI. Group of factors related to standards (H51, H52, H53, H54):

1. Use of local building codes;

2. Identification of technical requirements for building materials in burundian standards (assessment of safety levels, types and methods of testing, ...);

3. Establishment of a quality control system for construction works (entrance, operational and acceptance control);

4. Clarification of the roles and responsibilities of each participant in the construction process in the norms.

VII. Group of factors related to professional development (K71, K72).

1. Availability of centers and programs for retraining construction personnel to ensure the quality of construction work;

2. Possibility of advanced training in construction technology and organization.

A conceptual measurement model is defined (fig.3). Furthermore, the influence weights of each individual indicator on the corresponding group of factors are determined. Next, the influence weight of each group' factors on the complex quality indicator is determined. In the future, the research will be aimed at forming a mathematical model using structural equation modeling based on exploratory factor 
analysis and confirmatory factor analysis. Exploratory factor analysis and confirmatory factor analysis complement each other. While the first only allows you to identify the structure of the factor and the measurement model, the second allows you to compare the theory with field data (correction) and check the measurement model [14]. The model can be evaluated according to various methods:

1. the maximum likelihood parameter (ML);

2. the Generalized Least squares method or GLS, which consists of generalized least squares estimation;

3. the asymptotically nonparametric estimation methods [asymptotically distributionfree (ADF)] for large samples;

4. the weighted least squares or (WLS).

Moreover, the ML method is offered by default by several programs, including AMOS version 23 we are using in this research, and it turns out to be the most commonly used method for evaluating models with structural equations. In addition, $[15,16]$. Showed, based on several other studies, that this method "provides much better results, even if the hypothesis of the multiplicity of normal variables is violated". The method of structural equation modeling (SEM) allows you to determine the causal relationship between factors. The advantage of this method is that it does not need any assumptions about the distribution of data.

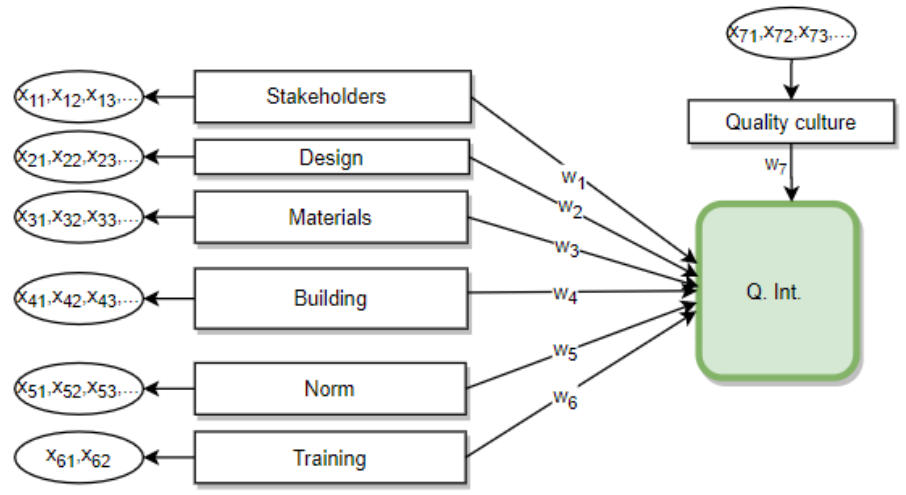

Fig. 3. Conceptual measurement model

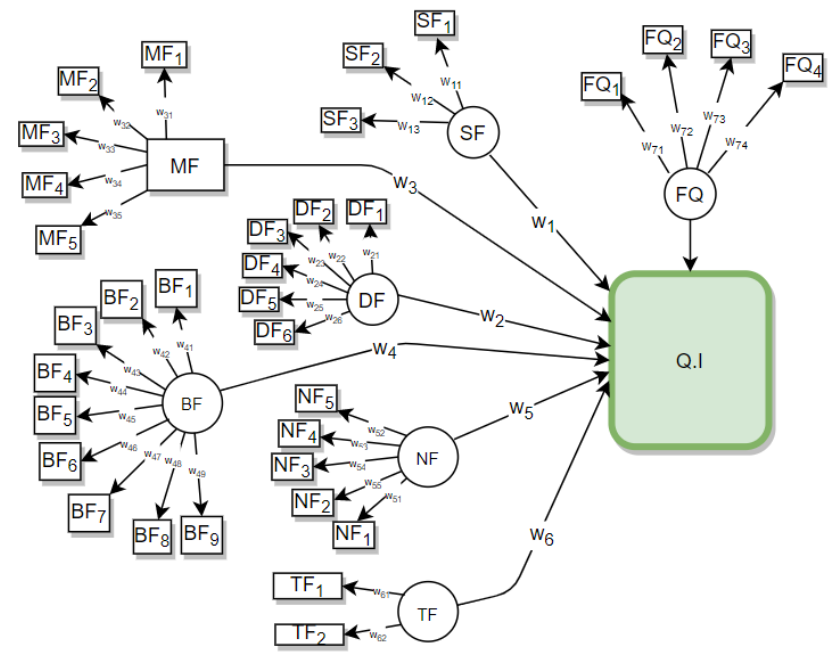

Fig. 4. Structural model 
Whereby:

$$
Q I=\sum_{i=1}^{n} W_{i} \sum_{j=1}^{k} w_{i j}
$$

- $Q I=$ Quality index;

- $W_{i}=$ weight of factor group $(i)$;

$-w_{i, j}=$ weight of quality indicator $(j)$ of factor $(i)$;

- $n=$ number of factors describing the $Q I$;

- $k=$ number of indicators included in the factor $(i)$.

\section{Conclusion}

The required level of quality can be achieved by meeting all organizational, technological and technical requirements. Since there is no ideal in life, the required level of quality can be achieved by using a tool that shows the optimal combination of quality parameters. A list of 34 indicators that have the greatest impact on the complex quality indicator according to experts are shown. These indicators were split into 7groups. The parameters used in this study are technical factors that appear at all stages of the project life cycle. Each of these parameters individually has its own impact. It is worth considering whether their combination is critical in terms of achieving the required level of quality of the multi apartment house. The next step of this research will be aimed at forming a mathematical model using structural equation modeling based on exploratory factor analysis and confirmatory factor analysis

\section{References}

1. A.A. Lapidus, Y. Ndayiragije, Formation of a comprehensive quality index for a largescale construction project, Science and business: development ways, 6 (96) 61-64 (2019).

2. A.A. Lapidus and N.Yves, Integrated Quality Index of Organizational and Technological Solutions for Implementation of Burundian Capital Master Plan, Materials Science Forum, 931, 1295-1300 (2018).

3. D.V. Topchiy, V.A. Skakalov, Development of an organizational and technological model for implementing construction control in multi-storey residential buildings, Scientific review, 11, 97-100 (2017).

4. A.A. Lapidus, Y. Ndayiragije, Standardization of masonry production as a factor in improving quality of housing construction in Burundi, Construction production, 1, 4550 (2020).

5. P. Patanakul, \& D. Milosevic, The effectiveness in managing a group of multiple projects: Factors of influence and measurement criteria, International journal of project management, 27(3), 216-233 (2009).

6. Ayodeji Oke, Clinton Aigbavboa, Ernest Dlamini, Factors Affecting Quality of Construction Projects in Swazilland, The Ninth International Conference on Construction in the 21st Century (CITC-9), March 5th-7th, 2017, Dubai, United Arab Emirates

7. J. von Meding et al., Critical Success Factors of Construction Project Quality in Brunei Darussalam, The international conference on Sustainable Built Environment for Now and the Future, March 26-27, 2012, Hanoi, Vietnam. 
8. A. Czajkowska, M. Kadłubek, Management of factors affecting quality of processes in construction enterprises, Polish journal of management studies, 11 (1) 28-38 (2015).

9. N. Janatyan, M. R. Hashemianfar, M. Kasaee, Integrated Model of Critical Success Factors of Construction Projects: A Case of Esfahan, Int. J. Res. Ind. Eng., 7 (3) 381395 (2018)

10. Y. Jaafer Altarawneh, Behrang Samadi, The relationship between critical success factors and success criteria in construction projects in the United Arab Emirates, International Journal of Advanced and Applied Sciences, 6 (7) 43-53 (2019).

11. R. Osei-Kyei, A. P. Chan, Implementing public-private partnership (PPP) policy for public construction projects in Ghana: critical success factors and policy implications, International journal of construction management, 17 (2) 113-123 (2017).

12. J.K. Pinto, J.E. Prescott, Variations in critical success factors over the stages in the project life cycle, Journal of management, 14 (1) 5-18 (1988).

13. J.K. Pinto, D.P. Slevin, Project success: Definitions and measurement techniques, Project management, 1, 67-72 (1988).

14. Joseph F. Hair Jr., William C. Black, Barry J. Babin, Rolph E. Anderson, Multivariate Data Analysis. Seventh Edition.

15. Patrice Roussel, François Durrieu, Eric Campoy, Méthodes d'équations structurelles recherche et applications en gestion.

16. Thu Anh Nguyen, Visuth Chovichien, Shin-ei Takano, Quantitative Weighting for Evaluation Indexes of Construction Project Success by Application of Structural Equation Modeling, International Journal of Construction Engineering and Management, 2 (3), 70-84 (2013). 